Journal of Physical Science, Vol. 28(2), 115-126, 2017

\title{
Oil Palm Frond Waste for the Production of Cellulose Nanocrystals
}

\author{
Noor Afeefah Nordin, Othman Sulaiman, ${ }^{*}$ Rokiah Hashim \\ and Mohamad Haafiz Mohamad Kassim \\ Division of Bioresource, Paper and Coatings Technology, \\ School of Industrial Technology, Universiti Sains Malaysia, \\ 11800 USM Pulau Pinang, Malaysia
}

*Corresponding author: osulaiman@gmail.com

Published online: 15 August 2017

To cite this article: Nordin, N. A. et al. (2017). Oil palm frond waste for the production of cellulose nanocrystals. J. Phys. Sci., 28(2), 115-126, https://doi.org/10.21315/jps2017.28.2.8

To link to this article: https://doi.org/10.21315/jps2017.28.2.8

\begin{abstract}
Oil palm frond (OPF) waste is one of the sustainable raw materials obtained after pruning of the OPFs. The objective of this study is to produce cellulose nanocrystals $(C N C)$ from OPFs by chemo-mechanical treatment. The multi-step process started with removal of extractives, wax and pectins by soxhlet extraction, followed by removal of lignin using sodium chlorite and $10 \%(\mathrm{v} / \mathrm{v})$ acetic acid. The bleached samples were then soaked in potassium hydroxide to remove the hemicellulose and finally underwent acid hydrolysis with 64\% (v/v) sulphuric acid hydrolysis for $1 \mathrm{~h}$. The CNC obtained were characterised using transmission electron microscopy (TEM), X-ray diffractions (XRD), Fourier transform infrared spectroscopy (FTIR) and thermal gravimetric analyser (TGA). The TEM images showed that the fibres were well dispersed and the treatment had reduced the size of fibres with average dimensions of $9.88 \mathrm{~nm}$ in diameter and $504.12 \mathrm{~nm}$ in length. The XRD results showed that the crystallinity index of the extracted cellulose fibres was $52.3 \%$ in comparison with the raw OPF, 35\%. The results from FTIR analysis showed some differences in the peaks and some were shifted due to removal of some components in the fibres. The TGA confirmed that the CNC had improved its thermal property by having an onset temperature of $258.34^{\circ} \mathrm{C}$ in comparison with the raw $O P F, 197.48^{\circ} \mathrm{C}$. This isolated CNC has great properties and can be used in many applications such as in biomedical field, food industry, cosmetics and wood products.
\end{abstract}

Keywords: Oil palm frond, cellulose nanocrystals, chemo-mechanical, OPF waste, isolated $\mathrm{CNC}$

(C) Penerbit Universiti Sains Malaysia, 2017. This work is licensed under the terms of the Creative Commons Attribution (CC BY) (http://creativecommons.org/licenses/by/4.0/). 


\section{INTRODUCTION}

Lignocellulosic materials are derived from agricultural waste and in Malaysia, a major contributor of biomass waste is from the oil palm (Elaeis guineensis) plantation. Malaysia has the second largest oil palm plantation area in the world which was reported to be 5.4 million hectares as of $2014 .{ }^{1}$ Oil palm plantation has generated a huge quantity of lignocellulosic resources consistently throughout the year in the form of oil palm trunk (OPT), empty fruit bunches (EFB), oil palm frond (OPF) and leaves. The OPF was reported to be the largest biomass which is $47 \%$ out of the total oil palm waste. ${ }^{2}$ Despite being a waste, OPF is abundant, readily available and inexpensive which makes it suitable to be used as a raw material for some value-added products. ${ }^{3}$ The current practice for disposal of OPF is by direct decaying and burning on the site while some small amount of OPF is used for composting. ${ }^{4}$ These actions are not desirable to the environment as they do not only pollute the environment, but will also cause harm to human beings due to the effect of polluted air. Hence, a proper waste management is needed to overcome the problems and minimise environmental issues.

OPF is spongy and fibrous in nature. ${ }^{5}$ Since it is highly fibrous, the OPF is suitable to be used in the production of cellulose nanocrystals (CNC) that has gained much attention in recent years. The main composition of the OPF are vascular bundles and parenchyma that contain extractives, cellulose, hemicellulose and lignin. Therefore, to obtain $\mathrm{CNC}$, the other components have to be removed by chemical, mechanical, chemo-mechanical or enzymatic treatment. Generally, cellulose has a high molecular weight homopolymer of $\beta$-D-glucopyranosyl repeating units joined by 1,4 -glycosidic linkages. ${ }^{6}$ The mechanical strength of cellulose is comparable to steel thus making it suitable as a reinforcing agent in some applications. In recent years, $\mathrm{CNC}$ has gained interest in the production of environmentally friendly and sustainable biocomposite materials for biomedical and industrial applications due to its biodegradability and renewable sources. ${ }^{7}$ For instance, it can be used for bone and tissue repair and reconstruction when mixed with suitable matrix. ${ }^{8}$ A study by Cherian et al. developed cellulose nanofibres from pineapple leaf and found that its versatility is suitable for the production of cardiovascular implants, repair of articulate cartilage, vascular grafts and artificial skin. ${ }^{9}$

Previous work has shown some isolation of $\mathrm{CNC}$ which is also known as nanowhiskers from various types of biomass such as from oil palm EFB, OPT, bagasse, cotton linters and others due to its potential for various applications. A work done by Saurabh et al. used retting OPF vascular bundles to produce cellulose nanowhiskers but the raw materials and methodology were different compared to this present work. ${ }^{10}$ Hence, this study was conducted to characterise the properties 
of $\mathrm{CNC}$ obtained from the whole fresh OPF and analyse the potential of this material to be used in the production of fibre-based materials.

The process of isolating $\mathrm{CNC}$ from the OPF depends on the target cellulose that one desires. Chemical treatment is done by subjecting the raw material with chemicals in order to remove the impurities while mechanical treatment is usually attributed to pulping process to obtain pulp before it is further purified. Chemomechanical treatment combines the use of chemicals and mechanical process in order to successfully remove lignin and hemicellulose. The enzymatic treatment uses few types of enzymes and is found to be mild in comparison with chemical and mechanical treatment. It will not cause damage to the fibres. However, the enzymatic treatment alone was reported to be unable to completely remove the lignin and hemicellulose in the samples. ${ }^{11}$ Therefore, it is crucial for researchers to find the best treatment for the isolation of $\mathrm{CNC}$ before it is being used for further application.

Research by Fahma et al. on the production of cellulose nanofibre from oil palm EFB showed that the optimum condition was obtained by combining chemical and mechanical treatment. ${ }^{12}$ Henriksson and Berglund developed an environmentally friendly method for the production of microfibrillated cellulose (MFC) by using pulping and enzyme. ${ }^{13}$ It was found that the MFC has a more favourable structure than nanofibres obtained from hydrolysis by strong acid. A work done by Bhattacharya et al. produced cellulose microfibers from bagasse and proved that $60 \%(\mathrm{v} / \mathrm{v})$ sulphuric acid hydrolysis managed to almost completely remove the amorphous structure without giving significant damage to the crystal structure. ${ }^{14}$

\section{EXPERIMENTAL}

\subsection{Materials}

The OPFs were obtained from oil palm plantation in Kuala Selangor, Selangor, Malaysia. The fronds were debarked and cut into small pieces prior to drying in the oven at a temperature of $50^{\circ} \mathrm{C}$ for $24 \mathrm{~h}$ to avoid fungal attack. After drying, the fronds were ground and sieved using a 70 mesh. The samples that passed through the sieved were used for the isolation of cellulose nanocrystals.

\subsection{Extraction of Raw Oil Palm Frond}

A total of $24 \mathrm{~g}$ of OPF samples were used for the extraction to remove extractives using the soxhlet extractor. The mixture of ethanol and toluene were used as a 
solvent with a ratio of $2: 1$. The extraction was done for $6 \mathrm{~h}$ at a temperature of $60^{\circ} \mathrm{C} \pm 5$ until the colour of the solvent became clear. The extracted samples were washed with distilled water prior to drying. The samples were then dried in the oven of $50^{\circ} \mathrm{C}$ before being further used.

\subsection{Isolation of CNC}

Twenty grams of extractive free OPF samples were used for the isolation. They were soaked and shaken in sodium chlorite $\left(\mathrm{NaClO}_{2}\right)$ and $10 \%(\mathrm{v} / \mathrm{v})$ acetic acid alternately for four times, at a temperature of $70^{\circ} \mathrm{C}$ for $4 \mathrm{~h}$ and were subsequently washed with distilled water. This process is also known as bleaching process, which is aimed to eliminate the lignin in the OPF sample. The bleached samples were then soaked in $6 \%$ of potassium hydroxide $(\mathrm{KOH})$ solution under $20^{\circ} \mathrm{C}$ for $24 \mathrm{~h}$ to remove hemicellulose. After that, the fibres were washed with distilled water until it reached $\mathrm{pH} 7$. The fibres were then subjected to acid hydrolysis with the ratio of fibre to acid 1:10 by adding $200 \mathrm{ml}$ of $64 \%(\mathrm{v} / \mathrm{v})$ sulphuric acid at $45^{\circ} \mathrm{C}$ under strong agitation for $1 \mathrm{~h}$. The hydrolysis was terminated by adding $400 \mathrm{ml}$ of cold distilled water to the solution. The precipitate was resuspended in water and centrifuged at $10000 \mathrm{rpm}$ to remove the excess water. Hydrolysis was done using the dialysis tube to obtain suspension of $\mathrm{CNC}$ at $\mathrm{pH} 7$. When the fibres had reached constant $\mathrm{pH}$, they were homogenised, sonicated and freeze dried before they were ready to be used for analysis. ${ }^{9}$

\subsection{Transmission Electron Microscope Study}

The structure and size of the $\mathrm{CNC}$ were observed by transmission electron microscopy using a Philips CM 12 electron microscope. A drop of diluted CNC suspension was deposited on a carbon-coated grid and allowed to dry at room temperature. The diameter of the fibres were measured manually using an image analyser program, XL Docu. A total of 10 single fibres of each sample were measured, and the result was calculated as the mean value of the data from each set of measurements.

\subsection{X-ray Diffraction Analysis}

The X-ray diffraction analysis was performed to check the crystallinity index of the CNC. Structural and phase analyses of the samples were measured by using an X-ray diffractometer, Bruker Advance 8 with $\mathrm{CuK} \alpha$ radiation (wavelength of $1.5406 \AA$ A) generated at an operating voltage and current of $40 \mathrm{kV}$ and $30 \mathrm{~mA}$, respectively. The $\mathrm{CuK} \alpha$ radiation was filtered electronically with a Ni-filter. A 
$2 \theta$ angle range from $5^{\circ}$ to $60^{\circ}$ in reflection mode was scanned at $2^{\circ} / \mathrm{min}$. The crystallinity index was calculated based on the following Equation 1:

$\operatorname{CrI}(\%)=\left(\mathrm{I}_{200}-\mathrm{I}_{\mathrm{am}}\right) / \mathrm{I}_{200} \times 100$

where $I_{200}$ is the peak intensity corresponding to crystalline and $I_{a m}$ is the peak intensity of the amorphous fraction. ${ }^{15}$

\subsection{FTIR Spectrometry}

The presence of any changes in functional groups of the samples during the treatment was observed by FTIR spectroscopy. The pellets were prepared by mixing approximately $5 \mathrm{mg}$ of particles samples with $95 \mathrm{mg}$ of finely ground $\mathrm{KBr}$ before pressing it into a transparent pellet. Spectra were viewed using a Nicolet infrared spectrophotometer (Avatar 360 FT-IR E.S.P) machine. The spectra produced are transmittance mode between wave numbers of $4000 \mathrm{~cm}^{-1}$ and $500 \mathrm{~cm}^{-1}$.

\subsection{Thermal Gravimetric Analysis}

Thermogravimetric analysis was performed to determine the thermal properties of the OPF fibres for raw and CNC samples. The thermal stability data were collected on a Perkin Elmer TGA 7 thermogravimetric analyser under linear temperature conditions. The temperature was swept from $50^{\circ} \mathrm{C}$ to $800^{\circ} \mathrm{C}$ for samples of 10 $15 \mathrm{mg}$ placed in an aluminium pan at a heating rate of $10^{\circ} \mathrm{C} / \mathrm{min}$ under nitrogen atmosphere.

\section{RESULTS AND DISCUSSION}

\subsection{Transmission Electron Microscopy (TEM)}

The image from TEM in Figure 1 showed the structure of individual fibre. The dimensions of each fibre were measured and resulted in having the average width of $9.88 \mathrm{~nm}$ and $504.12 \mathrm{~nm}$ in length. The average aspect ratio of the fibre was 51.02. Based on the dimensions of width and length of the fibre, it is categorised as cellulose nanowhiskers. ${ }^{16}$ Since the fibres underwent acid hydrolysis treatment which managed to remove major amounts of its amorphous structure, therefore it is categorised as cellulose nanocrystals. ${ }^{17}$ It can be observed that the fibres were in the form of individual fibres and not in a bundle. This is due to the chemomechanical treatments subjected to the OPF during the isolation that successfully removed lignin and hemicellulose. 

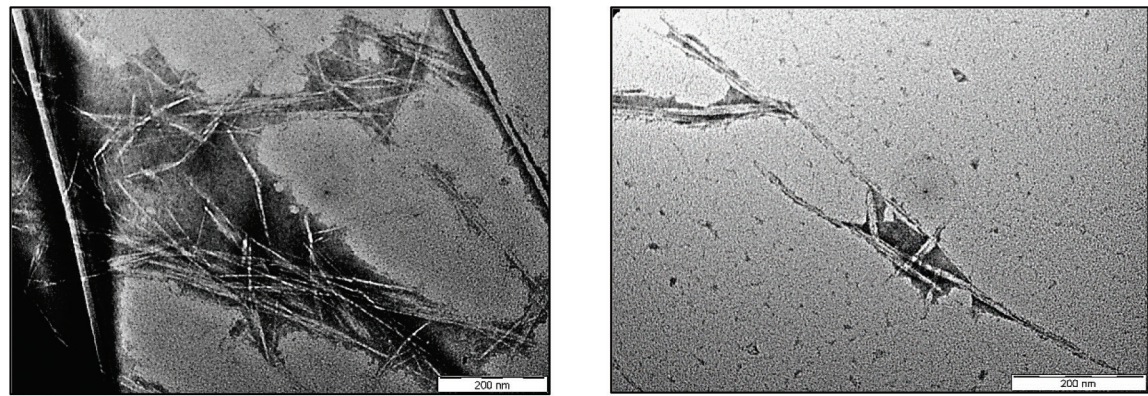

Figure 1: TEM image of $\mathrm{CNC}$ at 34000 magnification (left) and 50000 magnification (right).

\subsection{X-Ray Diffraction}

Naturally, celluloses are crystalline unit whereas lignin and hemicellulose are amorphous. The hemicellulose and lignin are categorised as non-celluloses polysaccharides and found surrounding the celluloses. In order to increase the crystallinity index of a sample, lignin and hemicellulose should be removed by chemical, mechanical or enzymatic treatment. Based on Figure 2, it can be observed that the peak of $\mathrm{CNC}$ is sharper than raw OPF. This indicates that the CNC possesses higher crystallinity index in comparison with raw OPF. Broader peaks correspond to more amorphous region as raw OPF has high amount of lignin and hemicellulose, meanwhile $\mathrm{CNC}$ has sharper peak due to elimination of hemicellulose and lignin after acid hydrolysis treatment. ${ }^{18}$

The diffractogram was presumed to represent typical cellulose I because it showed a single peak at $2 \theta=22^{\circ}$ and a shoulder in the region $2 \theta=19^{\circ}$. The crystallinity index were $54.5 \%$ and $36 \%$ for $\mathrm{CNC}$ and raw OPF respectively. The acid hydrolysis treatment managed to improve the crystallinity index of the CNC by $34 \%$. This finding complements a previous study on recovery of nanocellulose from OPF which obtained crystallinity index of $57.7 \% .{ }^{19}$ Crystallinity index obtained in this study was slightly lower than theirs and this could be attributed to the time of acid hydrolysis. A longer hydrolysis time may have partially degraded the crystalline structure of cellulose nancrystals hence resulted in a lower crystallinity index in this study. Based on the XRD analysis, it shows that the removal of lignin and hemicellulose could lead to an increment in crystallinity of the samples. 

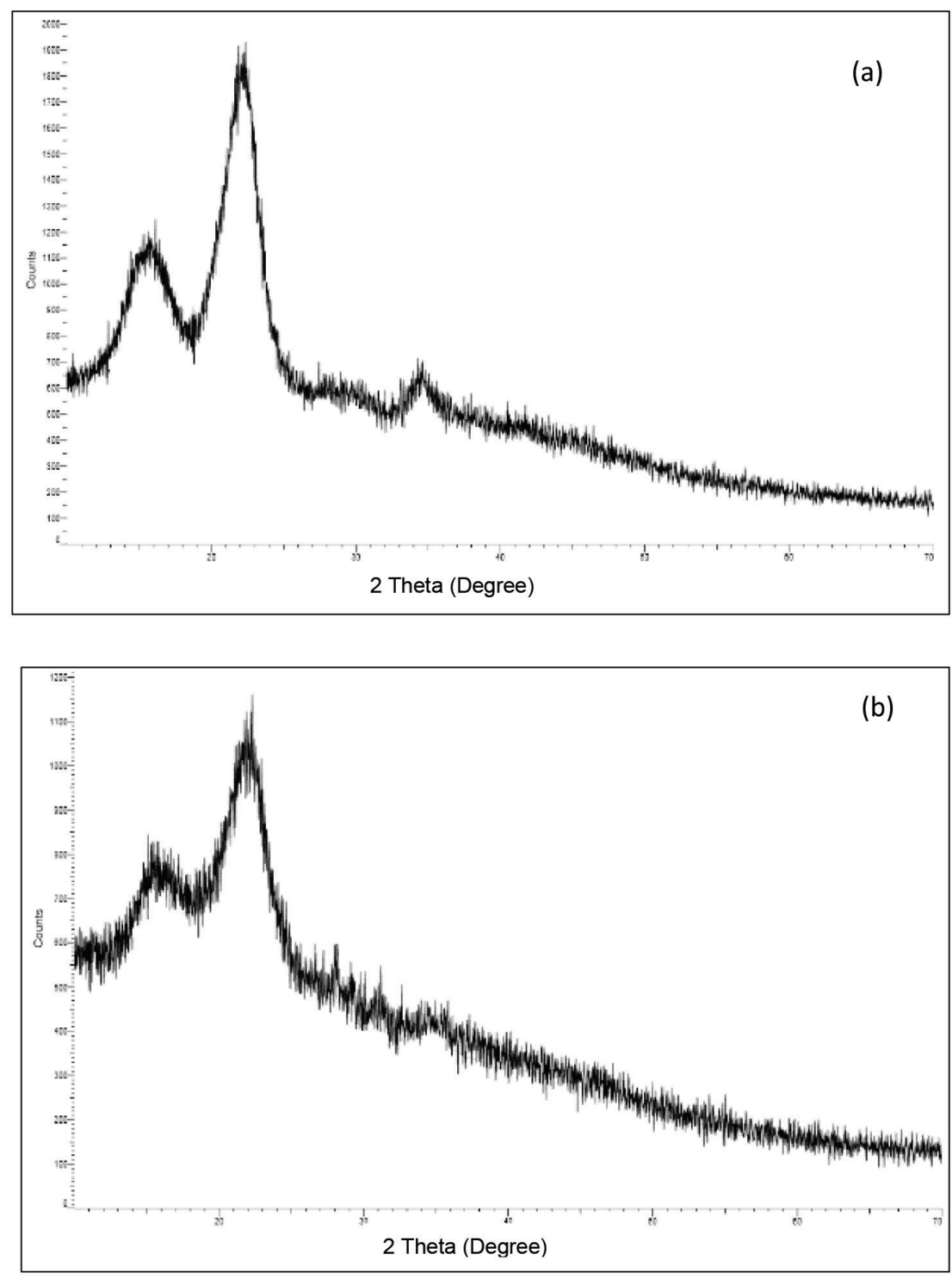

Figure 2: X-ray diffraction of (a) OPF CNC and (b) raw OPF.

\subsection{FTIR Spectroscopy}

The FTIR spectroscopy is a non-destructive method to study the physico-chemical properties of lignocellulosic materials. ${ }^{20}$ The spectroscopy was taken between the wavelengths of $4000 \mathrm{~cm}^{-1}$ and $450 \mathrm{~cm}^{-1}$. It can be observed in Figure 3 that the peaks look almost similar which indicated that both samples have the same chemical 
composition. The peaks in the 3,344-3,415 and 1,635-1,645 $\mathrm{cm}^{-1}$ regions were attributed to $\mathrm{O}-\mathrm{H}$ stretching and bending vibrations, respectively, of hydrogen bonded hydroxyl $(\mathrm{OH})$ groups of absorbed water, aliphatic primary and secondary alcohols found in cellulose, hemicellulose, and carboxylic acids in extractives. ${ }^{12,21}$ The peaks at $1,701-1,737 \mathrm{~cm}^{-1}$ in raw OPF corresponded to the $\mathrm{C}=\mathrm{O}$ stretching of hemicellulose and lignin while in $\mathrm{CNC}$, the peaks were shorter which indicated lesser amount of the chemical components available in the sample. It can also be observed that the peaks at $1,509-1,609 \mathrm{~cm}^{-1}$ which corresponded to $\mathrm{C}=\mathrm{C}$ aromatic skeletal vibration of lignin only appeared in raw OPF.

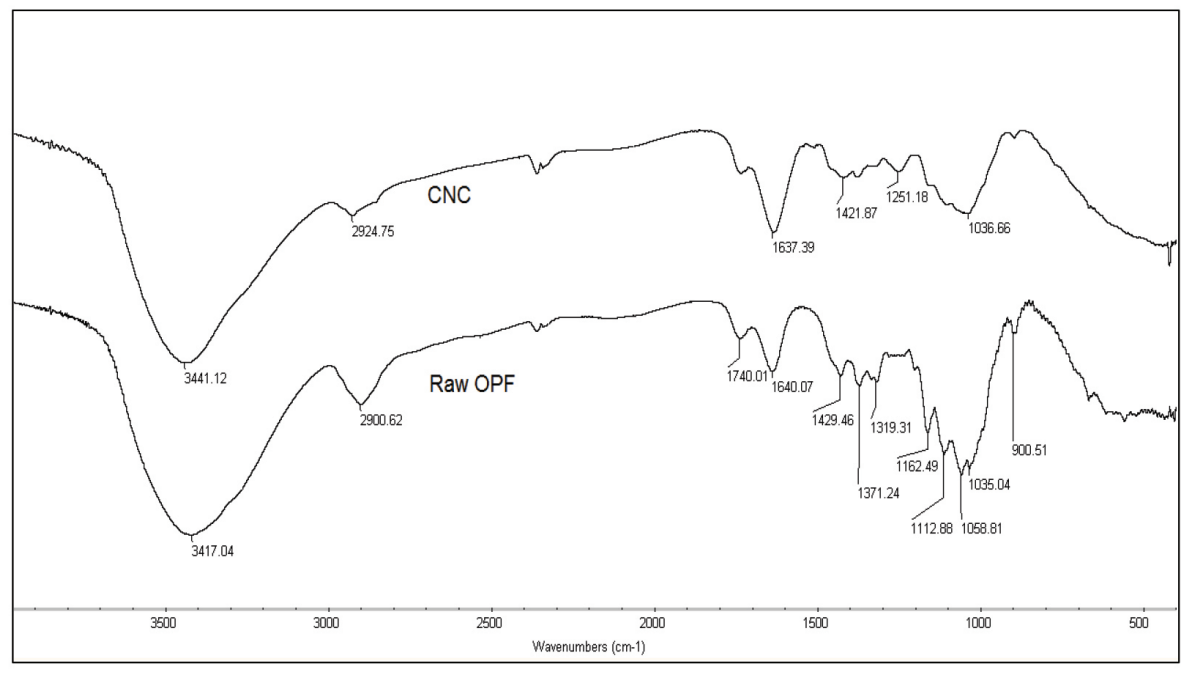

Figure 3: FTIR spectra of raw OPF and CNC.

The peaks at 1,058-1,060 and $896-900 \mathrm{~cm}^{-1}$ were attributed to the $\mathrm{C}-\mathrm{O}$ stretching and $\mathrm{C}-\mathrm{H}$ rocking vibrations of cellulose. ${ }^{22}$ The peaks indicated that the treatment managed to remove major part of hemicellulose and lignin. ${ }^{23}$

\subsection{Thermal Gravimetric Analysis}

The TGA determined thermal degradation of fibres and weight loss upon heating in order to identify their applicability when it is subjected to high temperature. The summary of thermal degradation data of $\mathrm{CNC}$ and raw OPF is tabulated in Table 1 , analysed at the temperatures at which $10 \%$ weight loss of the samples occurred. The char residue was calculated as percentage from the total amount of sample. 
Table 1: Thermal properties of CNC and raw OPF.

\begin{tabular}{lccc}
\hline Samples & Degradation temp $\left({ }^{\circ} \mathrm{C}\right) T_{10 \%}$ & Residual weight $(\%)$ & DTG peak temp $\left({ }^{\circ} \mathrm{C}\right) T_{\max }$ \\
\hline OPF CNC & 258.34 & 14.05 & 345.37 \\
Raw OPF & 197.48 & 24.91 & 328.26 \\
\hline
\end{tabular}

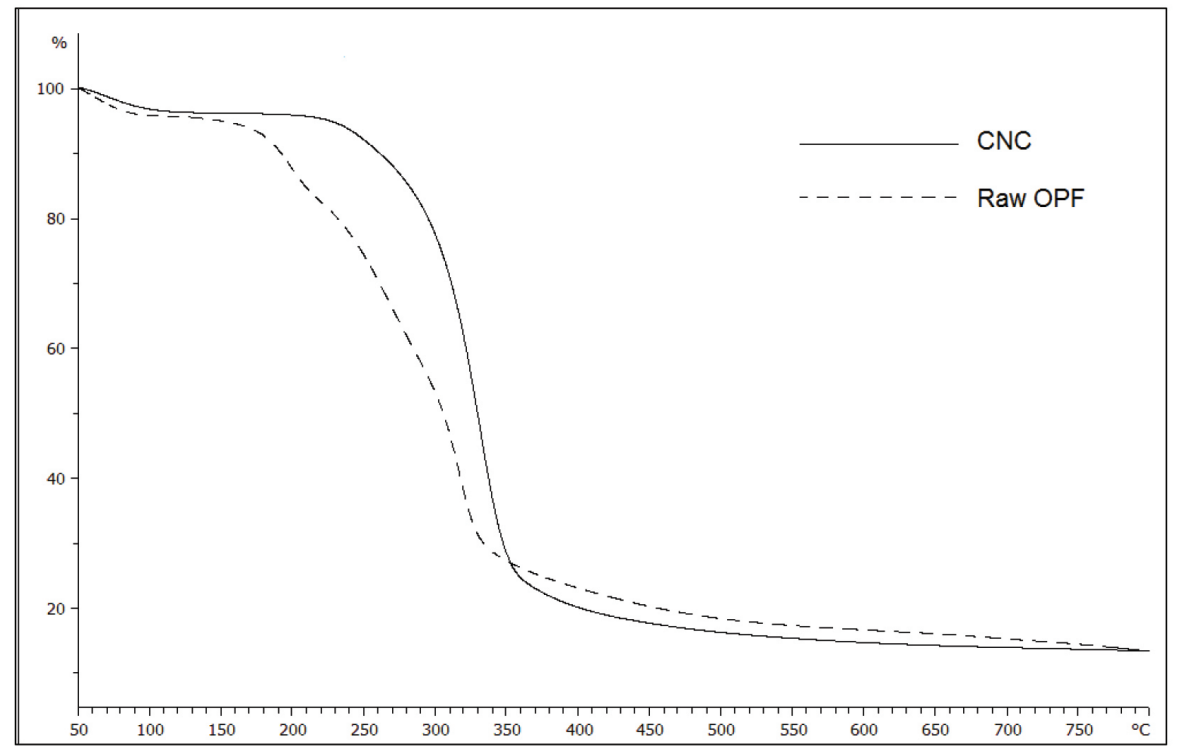

Figure 4: Thermal gravimetric curves of $\mathrm{CNC}$ and raw OPF.

Based on Figure 4, it was observed that there was an initial weight loss from $50^{\circ} \mathrm{C}$ to $150^{\circ} \mathrm{C}$ for both samples due to evaporation of water in cellulose fibre and nanocrystals while the temperature range between $150^{\circ} \mathrm{C}$ and $250^{\circ} \mathrm{C}$ showed depolymerisation of non-celluloses such as hemicellulose and lignin. Degradation of the $\alpha$-celluloses took place at temperature range between $300^{\circ} \mathrm{C}$ and $350^{\circ} \mathrm{C} .{ }^{24} \mathrm{It}$ can be observed that the major decomposition peak temperature of $\mathrm{CNC}$ occurred at $274.91^{\circ} \mathrm{C}$ while for raw $\mathrm{OPF}$, it occurred at $227.59^{\circ} \mathrm{C}$. These temperatures indicated where cellulose degradation takes place. The degradation of cellulosic materials starts from low to moderate temperatures. ${ }^{25}$ The degradation temperature of CNC was higher compared to raw OPF, ascribed to the removal of hemicellulose and lignin in the CNC thus improved its thermal property. According to Ouajai and Shanks, and Haafiz, a greater crystalline of cellulose nanowhiskers structure requires a higher degradation temperature..$^{26,27}$ 


\section{CONCLUSION}

This study showed that the properties of OPF CNC had improved compared to its original raw material. The images from TEM showed good dispersion of individual fibres resulted from the chemo-mechanical treatment. The XRD analysis showed increment of crystallinity index of CNC and was supported by the results from TGA. Improvement in thermal properties were attributed to the removal of hemicellulose and lignin in the OPF samples. The FTIR spectra confirmed the removal of noncellulosic polysaccharides by some shifting and change in intensities of the peaks. Based on the results obtained, $\mathrm{CNC}$ is suitable to be used for various applications in biomedical field such as tissue engineering, medical implants, drug delivery, wound dressing and cardiac devices due to their excellent properties. This study has shown that despite being a biomass waste, OPF could be used as a starting material for the production of biocomposites for high performance applications. The substitution of natural fibres to petroleum based materials would reduce the dependency on imported oil thus contributing to cost effectiveness.

\section{ACKNOWLEDGEMENTS}

The authors would like to acknowledge the Ministry of Higher Education (MOHE) for the MyPhd scholarship to Noor Afeefah Nordin and Universiti Sains Malaysia for Research University Grant 1001/PTEKIND/811255.

\section{REFERENCES}

1. Malaysia Palm Oil Council. (2014). Retrieved from http://www.mpoc.org. my/ on 19 November 2015.

2. Roslan, A. M. et al. (2014). Investigation of oil palm fronds properties for use as biomaterials and biofuels. Trop. Agr. Develop., 58(1), 26-29.

3. John, M. J. \& Thomas, S. (2008). Biofibers and biocomposites. Carbohydr. Polym., 71, 343-364, https://doi.org/10.1016/j.carbpol.2007.05.040.

4. Wan Rosli, W. D. et al. (2007). Pulp from oil palm frond by chemical process. Ind. Crops. Prod., 25, 89-94, https://doi.org/10.1016/j.indcrop.2006.07.005.

5. Sulaiman, O. et al. (2012). The potential of oil palm trunk biomass as an alternative source for compressed wood. Bioresour., 7(2), 2688-2706, https://doi.org/10.15376/biores.7.2.2688-2706.

6. Rowell, R. M. et al. (2005). Cell wall chemistry. In (Ed.) Rowell, R. M. Handbook of wood chemistry and wood composites. Florida: CRC Press, 37. 
7. Namvar, F. et al. (2014). Potential use of plant fibres and their composites for biomedical applications. Bioresour., 9(3), 5688-5706, https://doi. org/10.15376/biores.9.3.

8. Dhandayuthapani, B. et al. (2011). Polymeric scaffolds in tissue engineering application: A review. Int J Polym Sci., 2, 1-19, https://doi. org/10.1155/2011/290602.

9. Cherian, B. M. et al. (2010). Isolation of nanocellulose from pineapple leaf fibres by steam explosion. Carbohydr. Polym., 81(3), 720-725, https://doi. org/10.1016/j.carbpol.2010.03.046.

10. Saurabh, C. K. et al. (2016). Effect of hydrolysis treatment on cellulose nanowhiskers from oil palm (Elaeis guineensis) fronds: Morphology, chemical, crystallinity and thermal characteristics. Bioresour., 11(3), 67426755, https://doi.org/10.15376/biores.11.3.6742-6755.

11. Tonoli, G. H. D. et al. (2012). Cellulose micro/nanofibres from Eucalyptus kraft pulp: Preparation and properties. Carbohdr. Polym., 80(1), 80-88, https://doi.org/10.1016/j.carbpol.2012.02.052.

12. Fahma, F. et al. (2010). Isolation, preparation and characterization of cellulose nanofibers from oil palm empty fruit bunch (OPEFB). Cellulose, 17, 977-985, https://doi.org/10.1007/s10570-010-9436-4.

13. Henriksson, M. \& Berglund, L. A. (2007). Structure and properties of cellulose nanocomposite films containing melamine formaldehyde. Appl. Polym. Sci., 106(4), 2817-2824, https://doi.org/10.1002/app.26946.

14. Bhattacharya, D. et al. (2008). Isolation, preparation and characterization of cellulose microfibers obtained from bagasse. J. Carbohydr. Polym., 73, 371-377, https://doi.org/10.1016/j.carbpol.2007.12.005.

15. Segal, L. et al. (1959). An empirical method for estimating the degree of crystallinity of native celluloses using diffractometer. Text. Res., 29, 786794, https://doi.org/10.1177/004051755902901003.

16. Siro, I. \& Plackett, D. (2010). Microfibrillated cellulose and new nanocomposite materials: A review. Cellul., 17(3), 459-494, https://doi. org/10.1007/s10570-010-9405-y.

17. Hubbe, M. A., Rojas, O. J. \& Lucia, L. A. (2015). Green modification of surface characteristics of cellulosic materials at the molecular or nano scale: A review. Bioresour., 10(3), 6095-6206, https://doi.org/10.15376/ biores. 10.3.hubbe.

18. Elanthikkal, S. et al. (2010). Cellulose microfibres produced from banana plant wastes: Isolation and characterization. Carbohydr. Polym., 80, 852859. 
19. Mohaiyidin, M. S. et al. (2016). Characterization of nanocellulose recovery from Elaeis guineensis frond for sustainable development. Clean Technol. Environ. Policy, 18, 2503-2512, https://doi.org/10.1007/s10098-016-11912.

20. Sun, J. X. et al. (2004). Isolation and characterization of cellulose from sugarcane bagasse. Polym. Degrad. Stab., 84(2), 331-339, https://doi. org/10.1016/j.polymdegradstab.2004.02.008.

21. Surip, S. N. et al. (2012). Microscopy observation on nanocellulose from kenaf fibre. Adv. Mater. Sci., 488-489, 72-75, https://doi.org/10.4028/www. scientific.net/amr.488-489.72.

22. Rosa, M. F. et al. (2010). Cellulose nanowhiskers from coconut husk fibers: Effect of preparation conditions on their thermal and morphological behavior. Carbohydr. Polym., 81, 82-93, https://doi.org/10.1016/j. carbpol.2010.01.059.

23. Cetin, N. S. \& Ozmen, N. (2011). Acetylation of wood components and fourier transform infra-red spectroscopy studies. Afr. J. Biotechnol., 10(16), 3091-3096, https://doi.org/10.5897/AJB10.2630.

24. Sonia, A. \& Priya Dasan, K. (2013). Chemical, morphology and thermal evaluation of cellulose microfibers obtained from Hibiscus sabdariffa. Carbohydr. Polym., 92, 668-674, https://doi.org/10.1016/j. carbpol.2012.09.015.

25. Jonoobi, M. et al. (2010). Mechanical properties of cellulose nanofiber (CNF) reinforced polylactic acid (PLA) prepared by twin screw extrusion. Compos. Sci. Technol., 70(12), 1742-1747, https://doi.org/10.1016/j. compscitech.2010.07.005.

26. Ouajai, S. \& Shanks, R. A. (2005). Morphology and structure of bioscouring hemp fibre. J. Macromol. Biosci., 5, 124-134, https://doi.org/10.1002/ mabi.200400151.

27. Haafiz, M. K. M. et al. (2014). Isolation and characterization of cellulose nanowhiskers from oil palm biomass microcrystalline cellulose. Carbohydr. Polym., 103, 119-125, https://doi.org/10.1016/j.carbpol.2013.11.055. 